\title{
Methods for Assessing Expiratory Flow Limitation during Tidal Breathing in COPD Patients
}

\author{
Nickolaos G. Koulouris, Georgios Kaltsakas, \\ Anastasios F. Palamidas, and Sofia-Antiopi Gennimata
}

Respiratory Function Laboratory, 1st Department of Respiratory Medicine, Medical School, National and
Kapodistrian University of Athens and "Sotiria" Chest Disease Hospital, 11527 Athens, Greece

Correspondence should be addressed to Nickolaos G. Koulouris, koulnik@med.uoa.gr

Received 11 June 2012; Accepted 10 August 2012

Academic Editor: Kiriakos Karkoulias

Copyright (๑) 2012 Nickolaos G. Koulouris et al. This is an open access article distributed under the Creative Commons Attribution License, which permits unrestricted use, distribution, and reproduction in any medium, provided the original work is properly cited.

Patients with severe COPD often exhale along the same flow-volume curve during quite breathing as during forced expiratory vital capacity manoeuvre, and this has been taken as indicating expiratory flow limitation at rest $\left(\mathrm{EFL}_{\mathrm{T}}\right)$. Therefore, $\mathrm{EFL}_{\mathrm{T}}$, namely, attainment of maximal expiratory flow during tidal expiration, occurs when an increase in transpulmonary pressure causes no increase in expiratory flow. $\mathrm{EFL}_{\mathrm{T}}$ leads to small airway injury and promotes dynamic pulmonary hyperinflation with concurrent dyspnoea and exercise limitation. In fact, $\mathrm{EFL}_{\mathrm{T}}$ occurs commonly in COPD patients (mainly in GOLD III and IV stage) in whom the latter symptoms are common. The existing up-to-date physiological methods for assessing expiratory flow limitation $\left(\mathrm{EFL}_{\mathrm{T}}\right)$ are reviewed in the present work. Among the currently available techniques, the negative expiratory pressure (NEP) has been validated in a wide variety of settings and disorders. Consequently, it should be regarded as a simple, non invasive, most practical, and accurate new technique.

\section{Introduction}

Some experts use the term chronic airflow limitation as a synonym for chronic obstructive pulmonary disease (COPD) to indicate the reduction in maximum expiratory flow that occurs in this disease (and indeed in other pulmonary diseases). Patients with severe COPD often exhale along the same flow-volume curve during quite breathing as during forced expiratory vital capacity manoeuvre, and this has been taken as indicating flow limitation at rest $\left(\mathrm{EFL}_{\mathrm{T}}\right)$. Consequently, the term tidal expiratory flow limitation $\left(\mathrm{EFL}_{\mathrm{T}}\right)$ is used to indicate that maximal expiratory flow is achieved during tidal breathing at rest or during exercise. This is characteristic of intrathoracic flow obstruction. The former term does not imply that $\mathrm{EFL}_{\mathrm{T}}$ actually occurs during tidal breathing [1]. The location of expiratory flow limitation is considered to be in the central airways (4th-7th generation) and move to the periphery during forced expiratory manoeuvres. It is located beyond the 7th (i.e., from the 8th onwards) generation during tidal breathing [2-4].
Tidal expiratory flow limitation $\left(\mathrm{EFL}_{\mathrm{T}}\right)$ [5-8] plays a central role according to a recent hypothesis [5] on the transition from small airways disease (SAD) to overt COPD in smokers. $\mathrm{EFL}_{\mathrm{T}}$ implies inhomogeneity of ventilation distribution with concurrent impairment of gas exchange and unevenly distributed stress and strain within the lung, which is amplified by tissue interdependence $[6,7]$ and may lead to small airway injury [5-8]. Initially, the latter is histologically characterized by denuded epithelium, rupture of alveolar-airway attachments, and increased number of polymorphonuclear leucocytes [5-7]. Studies in which heliox $\left(80 \% \mathrm{He} / 20 \% \mathrm{O}_{2}\right)$ was administered in COPD patients provided also corroborative evidence that $\mathrm{EFL}_{\mathrm{T}}$ was located in the peripheral airways [2-4]. EFL $\mathrm{T}_{\mathrm{T}}$ promotes dynamic pulmonary hyperinflation and PEEPi with concurrent dyspnoea and exercise limitation [8]. In fact, $\mathrm{EFL}_{\mathrm{T}}$ occurs commonly in GOLD III and IV stage patients causing dynamic hyperinflation and severe dyspnoea [9]. It should be noted that the important role of expiratory flow limitation in COPD patients has been studied in a variety of clinical settings (during mechanical ventilation 
and exercise, correlation with dyspnoea, orthopnoea, and the other lung function indexes, before and after bronchodilatation, various postures).

\section{Clinical Significance of EFL}

The important role of $\mathrm{EFL}_{\mathrm{T}}$ in chronic dyspnoea and exercise impairment for a surprisingly wide range of clinical circumstances was enlightened by the techniques of detecting it, but mainly by the use of negative expiratory pressure (NEP) technique. $\mathrm{EFL}_{\mathrm{T}}$ measured with the NEP technique is a much better predictor of chronic dyspnoea than $\mathrm{FEV}_{1}$, and $\mathrm{FEV}_{1}$ is not a specific predictor of $\mathrm{EFL}_{\mathrm{T}}$ in COPD patients. These findings suggest that $\mathrm{EFL}_{\mathrm{T}}$ measured by the NEP technique may be more useful in the evaluation of dyspnoea in COPD patients than spirometric measurements [10].

The improvement of inspiratory capacity (IC) after bronchodilator administration [11], which is mainly limited to patients with EFL at rest and therefore usually exhibits a reduction of baseline IC, entails reduction in dyspnoea both at rest and during light exercise [12]. The fact that after bronchodilator administration there is a significant reduction of dynamic hyperinflation (DH) only in patients with EFL at rest further supports the usefulness of stratifying COPD patients in subgroups with and without EFL in order to predict an improvement in DH [11]. COPD patients with EFL may experience less breathlessness after a bronchodilator, at least during light exercise, than those without EFL. This beneficial effect, which is closely related to an increase in IC at rest, occurs even in the absence of a significant improvement of $\mathrm{FEV}_{1}$ [12]. Though, in the past, bronchodilator testing focused on changes of $\mathrm{FEV}_{1}$, the scrutiny of changes in IC in non-EFL $L_{T}$ and $\mathrm{EFL}_{\mathrm{T}} \mathrm{COPD}$ patients should provide useful information. In contrast, the detection of EFL ${ }_{T}$ did not predict the changes of EELV or dyspnoea occurring after bronchodilation [13].

Díaz et al. [14] found that IC was the only spirometric parameter, in which there was almost no overlap between non-EFL $\mathrm{T}_{\mathrm{T}}$ and $\mathrm{EFL}_{\mathrm{T}} \mathrm{COPD}$ patients. The non-EFL $\mathrm{T}_{\mathrm{T}}$ patients had almost all normal IC whilst the EFL $\mathrm{E}_{\mathrm{T}}$ all had $<80 \%$ pred in a group of 52 COPD patients. Linear regression analysis performed separately for these $\mathrm{EFL}_{\mathrm{T}}$ and non-EFL $\mathrm{T}_{\mathrm{T}}$ patients showed that in the EFL $\mathrm{T}_{\mathrm{T}}$ patients the sole predictor of exercise capacity was $\mathrm{IC} \%$ pred, whilst in the non-EFL $\mathrm{T}_{\mathrm{T}}$ the ratio $\mathrm{FEV}_{1} / \mathrm{FVC} \%$ pred was the sole predictor. Díaz et al. [15] also reported that in $\mathrm{EFL}_{\mathrm{T}}$ COPD patients, the maximal tidal volume and hence maximal oxygen consumption are closely related to the reduced IC. The EFL $\mathrm{EL}_{\mathrm{T}}$ patients also exhibited a significant increase in $\mathrm{PaCO}_{2}$ and a decrease in $\mathrm{PaO}_{2}$ during peak exercise. O'Donnell et al. [16] extended the findings of Díaz et al. $[14,15]$ reporting that since the pathophysiological hallmark of COPD is EFL (occurring during exercise and in the advanced disease even at rest), the latter promoted DH which was correlated best with resting IC. DH curtailed $\mathrm{V}_{\mathrm{T}}$ response to exercise. The inability to expand $\mathrm{V}_{\mathrm{T}}$ in response to increasing ventilatory demand contributed to exercise intolerance in COPD.

The main finding of these studies was that detection of tidal EFL plays an important role in identifying the factors that limit exercise tolerance because resting EFL clearly separates two populations of patients with significant differences in exercise tolerance. More importantly, their detection provides useful information about the mechanisms limiting exercise tolerance. The detection of EFL during exercise should be carried out also using the NEP technique, as the conventional method for detecting flow limitation based on comparison of tidal with maximal flow-volume curves is not reliable [17]. In the presence of tidal EFL, DH appears to be the main determinant of exercise performance and the magnitude of resting IC, a well-recognized marker of $\mathrm{DH}$, the best clinical predictor $[14,17]$.

EFL may be absent at rest but can be developed and hence detected during any exercise level by the use of NEP. That explains the fact that COPD patients, who are not hyperinflated at rest, develop DH during exercise [17]. It should be noted here that there are instances when $\mathrm{DH}$ (reflected by a reduced IC) can occur in the absence of tidal EFL $[18,19]$, and the presence of tidal EFL may not necessarily result in $\mathrm{DH}$ if the available expiratory flow is sufficient to sustain resting ventilation without the need to increase EELV. This is reflected by the fact that there are patients with $\mathrm{EFL}_{\mathrm{T}}$ and normal IC. Thus, measurement of IC and detection of EFL are complimentary ways for assessing bronchodilator and exercise responsiveness in COPD patients.

It was found that almost all COPD patients who require mechanical ventilation are flow-limited over the entire range of tidal expiration and that the supine posture promotes flow limitation [20].

Despite these potentially adverse consequences of EFL, its prevalence has not been extensively studied until recently, probably due to the lack of simple and noninvasive techniques. The aim of this work was to review the existing physiological techniques of assessing tidal expiratory flow limitation $\left(\mathrm{EFL}_{\mathrm{T}}\right)$.

\section{Oesophageal Balloon Techniques}

3.1. Fry Method. The definition of EFL implies that a further increase in transpulmonary pressure will cause no further increase in expiratory flow [21]. Therefore, direct assessment of expiratory flow limitation requires determination of isovolume relationships between flow and transpulmonary pressure $(F-P)$. Fry et al. [22] were the first who developed such curves in 1950s. The explanation of an isovolumic pressure flow curve lies in understanding its construction. Flow, volume and oesophageal pressure (Poes) are measured simultaneously during the performance of repeated expiratory vital capacity efforts by a subject seated in a volume body plethysmograph, in which gas compression artifact is corrected. The subject is instructed to exhale with varying amounts of effort that are reflected by changes in Poes. From a series of such efforts $(\sim 30)$, it is possible to plot flow against Poes at any given lung volume [21]. The flow reached a plateau at a low positive pleural pressure and that once maximum flow for that volume is reached, it remains constant despite increasing Poes by making expiratory efforts of increasing intensity. 
3.2. Mead-Whittenberger's Method. The Mead-Whittenberger method [23] directly relates alveolar pressure to flow. Mead-Whittenberger's graphs can be obtained by plotting the flow measured at the airway opening versus the resistive pressure drop during a single breath. In such a way the phenomenon of flow limitation is documented.

These techniques are technically complex and time consuming. Furthermore, these techniques are invasive because they require the insertion of an oesophageal balloon $[22,23]$.

3.3. Conventional (Hyatt's) Method. Until recently, the "conventional" method used to detect expiratory flow-limitation during tidal breathing was the one proposed by Hyatt [24] in 1961. It consists in superimposing a flow volume loop of a tidal breath within a maximum flow-volume curve. This analysis and the "concept of EFL" have been the basics for understanding respiratory dynamics. Flow limitation is not present when the patient breaths tidally below the maximal expiratory flow-volume (MEFV) curve. According to this technique, normal subjects do not reach flow limitation even at maximum exercise $[1,25]$. In contrast, flow limitation is present when a patient breathes tidally along or higher than the MEFV curve. Patients with severe chronic obstructive pulmonary disease (COPD) may exhibit flow limitation even at rest, as reflected by the fact that they breathe tidally along or above their maximal flow-volume curve [1,21-25]. However, the conventional method to detect flow limitation based on comparison of maximal to tidal expiratory flowvolume curves suffers from several methodological deficiencies. These include the following.

(a) Thoracic Gas Compression Artefacts. Volume should be measured with a body-box, instead of using, as is common practice, a pneumotachograph or a spirometer in order to minimize such errors [26]. Consequently, in practice, flow limitation can be assessed only in seated subjects at rest.

(b) Incorrect Alignment of Tidal and Maximal Expiratory F-V Curves. Such alignment is usually made considering the total lung capacity (TLC) as a fixed reference point. This assumption may not always be valid [27, 28].

(c) Effect of Previous Volume and Time History. Comparison of tidal and maximal $F-V$ curves is incorrect, since the previous volume and time history of a spontaneous tidal breath is necessarily different from that of an FVC manoeuvre. Therefore, it is axiomatic that comparison of tidal with maximal $F-V$ curves is problematic. In fact, there is not a single maximal $F-V$ curve but rather a family of different curves, which depend on the time course of the inspiration preceding the FVC manoeuvre [29-31].

(d) Respiratory Mechanics and Time Constant Inequalities. These are different during the tidal and maximal expiratory efforts again making comparisons of the two $F$ - $V$ curves problematic [32-34].

(e) Exercise. Exercise may result in bronchodilation or bronchoconstriction and other changes of lung mechanics, which may also affect correct comparisons of the two $F-V$ curves [35].

(f) Patient's Cooperation. Another important limitation of the conventional method is that it requires patient's cooperation. This is not always feasible $[27,28]$.
In fact, it has been clearly demonstrated in several studies $[11,17,36,37]$ comparing the NEP with the conventional technique that the latter is not accurate. As a result, the use of the conventional method is no longer recommended.

\section{The Negative Expiratory Pressure (NEP) Technique}

In order to overcome these technical and conceptual difficulties, the negative expiratory pressure (NEP) technique has been introduced $[10,17,27,36]$. The NEP technique has been first applied and validated in mechanically ventilated ICU patients by concomitant determination of isovolume flow-pressure relationships [38]. This method does not require performance of FVC manoeuvres, collaboration on the part of the patient, or use of a body-box. It can be used during spontaneous breathing in any body position [39], during exercise $[17,40]$, and ICU settings [20]. With this technique the volume and time history of the control and test expiration are axiomatically the same.

Briefly, a flanged plastic mouthpiece is connected in series to a pneumotachograph and a T-tube (Figure 1). One side of the T-tube is open to the atmosphere, whilst the other side is equipped with a one-way pneumatic valve, which allows for the subject to be rapidly switched to negative pressure generated by a vacuum cleaner or a Venturi device. The pneumatic valve consists of an inflatable balloon connected to a gas cylinder filled with pure helium and a manual pneumatic controller. The latter permits remote-control balloon deflation, which is accomplished quickly $(30-60 \mathrm{~ms})$ and quietly, allowing rapid exposure to negative pressure during expiration (NEP). Alternatively, a solenoid rapid valve can be used. The NEP (usually set at about $-5 \mathrm{~cm} \mathrm{H}_{2} \mathrm{O}$ ) can be adjusted with a potentiometer on the vacuum cleaner or by controlling the Venturi device. Airflow $(\dot{V})$ is measured with the heated pneumotachograph and pressure at the airway opening (Pao) is simultaneously measured through a side port on the mouthpiece (Figure 1). Volume $(V)$ is obtained by digital integration of the flow signal, and correction of electrical drift is mandatory [36]. While performing the testing, the subjects should be watched closely for leaks at the mouthpiece. Only those tests, in which there is no leak, are valid [41]. Tidal EFL is assessed while seated upright in a comfortable chair or if needed lying supine on a comfortable couch, at least $2 \mathrm{~h}$ after eating or taking coffee. Patients are asked to breathe room air through the equipment assembly with the noseclip on (Figure 1). Each subject has an initial 10-15 min trial run, in order to become accustomed to the apparatus and procedure. The flow, volume, and pressure are continuously monitored on the computer screen. When regular breathing is resumed, a series of test breaths are performed with regular breaths in between the test breaths, in which NEP is applied at the beginning of expiration and maintained throughout the ensuing expiration [36].

The NEP technique is based on the principle that in the absence of flow limitation, the increase in pressure gradient between the alveoli and the airway opening caused by NEP should result in increased expiratory flow. By contrast, in flow-limited subjects application of NEP should not 


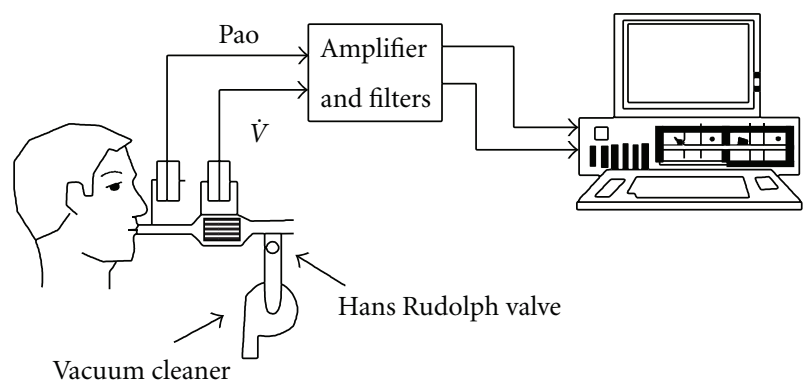

Figure 1: Schematic diagram of equipment setup. Pao: pressure at the airway opening; $\dot{V}$ : gas flow (from [36]).

change the expiratory flow. Our analysis essentially consists in comparing the expiratory $\dot{V}-V$ curve obtained during a control breath with that obtained during the subsequent expiration in which NEP is applied [36].

Subjects in whom application of NEP does not elicit an increase of flow during part or all of the tidal expiration (Figures 2(b) and 2(c)) are considered flow-limited (EFL). By contrast, subjects in whom flow increases with NEP throughout the control tidal volume range (Figure 2(a)) are considered as non-flow-limited (non-EFL ${ }_{\mathrm{T}}$ ). If tidal EFL is present when NEP is applied, there is a transient increase of flow (spike), which mainly reflects sudden reduction in volume of the compliant oral and neck structures. To a lesser extent a small artefact due to common-mode rejection ratio of the system of measuring flow may also contribute to the flow transients $[10,36]$. Such spikes are useful markers of EFL.

The degree of flow limitation can be assessed using three different EFL $_{\mathrm{T}}$ indices: (a) as a continuous variable expressed as $\% \mathrm{~V}_{\mathrm{T}}$ in both seated and supine positions (Figure 2) [36], (b) as a discrete variable in the form of three categories classification, that is, non-EFL $\mathrm{E}_{\mathrm{T}}$ both seated and supine, $\mathrm{EFL}_{\mathrm{T}}$ supine but not seated, and $\mathrm{EFL}_{\mathrm{T}}$ both seated and supine [36], and (c) as discrete variable in the form of the five-category classification (5-point $\mathrm{EFL}_{\mathrm{T}}$ score) [10].

In all studies employing the NEP technique, the latter was not associated with any unpleasant sensation, cough, or other side effects $[10,17,36]$. The finding of O'Donnell et al. [42] that application of $-9.7 \mathrm{~cm} \mathrm{H}_{2} \mathrm{O} / \mathrm{L} / \mathrm{s}$ of expiratory assistance for 4 min during inspiration and expiration caused unpleasant respiratory sensation can be attributed to negative pressure application differences, that is, NEP, usually at $-5 \mathrm{~cm} \mathrm{H}_{2} \mathrm{O}$ level, is applied only during expiration every 510 breaths intervals.

The use of the NEP technique during tidal flow-volume analysis studies has led to realization of the important role of expiratory flow limitation in exertional dyspnoea and ventilatory impairment for a surprisingly wide range of clinical circumstances, for example, before and after bronchodilation, exercise, ICU, and heliox administration at rest and during exercise $[8,43,44]$. Up to date, no study has questioned reliability and accuracy of the NEP technique. Currently, therefore, the NEP technique can be regarded as the new gold standard to detect $\mathrm{EFL}_{\mathrm{T}}$, if one takes into account the pros and cons of each available technique. It is a novel, simple, non-invasive, useful research and clinical lung function tool.

\section{Submaximal Expiratory Manoeuvres}

Pellegrino and Brusasco [45] proposed an alternative technique to detect expiratory flow limitation. EFL $\mathrm{E}_{\mathrm{T}}$ was inferred from the impingement of the tidal flow-volume loop on the flow recorded during submaximally forced expiratory manoeuvres initiated from end-tidal inspiration in a bodybox. After regular breathing with no volume drift, the subject performs a forced expiration from end-tidal inspiration without breath holding (partial expiratory manoeuvre). Care is taken to coach the subjects not to slow down the inspiration preceding the partial forced manoeuvre, thus minimizing the dependence of forced flows on the time of the preceding inspiration. A deep inspiration to TLC recorded soon after the gentle forced manoeuvre allowed the loops to be superimposed and compared at absolute lung volume. Flow limitation is defined as the condition of tidal expiratory flow impinging on the maximal flow generated during the gentle forced expiratory manoeuvre. Since this method requires a body box measurements cannot be made in different body postures, ICU, or during exercise testing.

\section{Squeezing the Abdomen during Expiration}

Workers in Brussels have shown that manual compression of the abdomen coinciding with the onset of expiration can be used as a simple way of detecting flow limitation at rest [46] and during exercise [47]. With one hand placed on the lower back of the patient and other applied with the palm at the level of the umbilicus perpendicular to the axis between the xiphoid process and the pubis, the operator first detects a respiratory rhythm by gentle palpation, and then after warning the subject applies a forceful pressure at the onset of expiration. As in the NEP technique, the resulting expiratory flow-volume loop recorded at the mouth is superimposed on the preceding tidal breath. Failure to increase expiratory flow indicates flow limitation. This technique produces clear differences between normal subjects and patients with COPD. The presence of flow limitation during exercise detected during exercise in COPD patients was associated with increases in the end-expiratory lung volume (EELV) [47]. Interestingly, not all subjects with COPD exhibited 


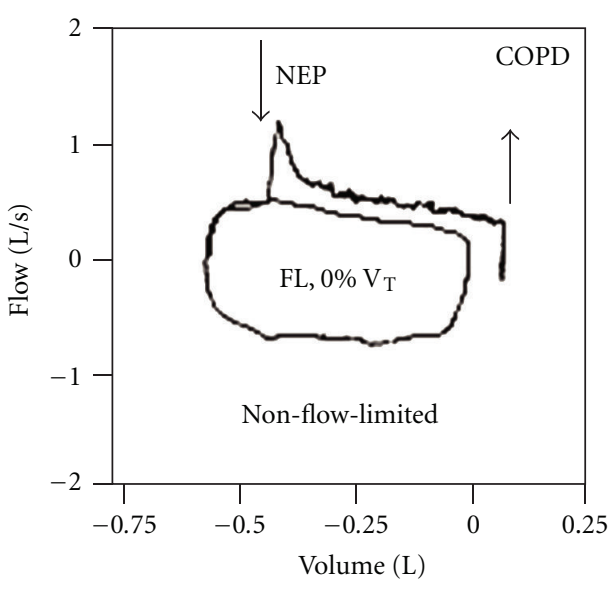

(a)

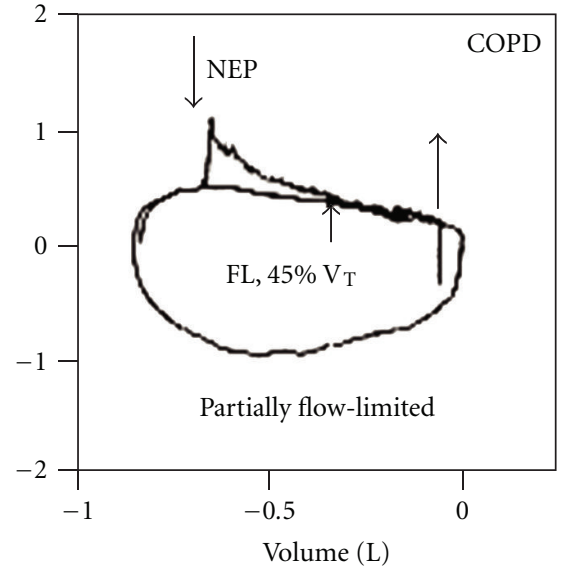

(b)

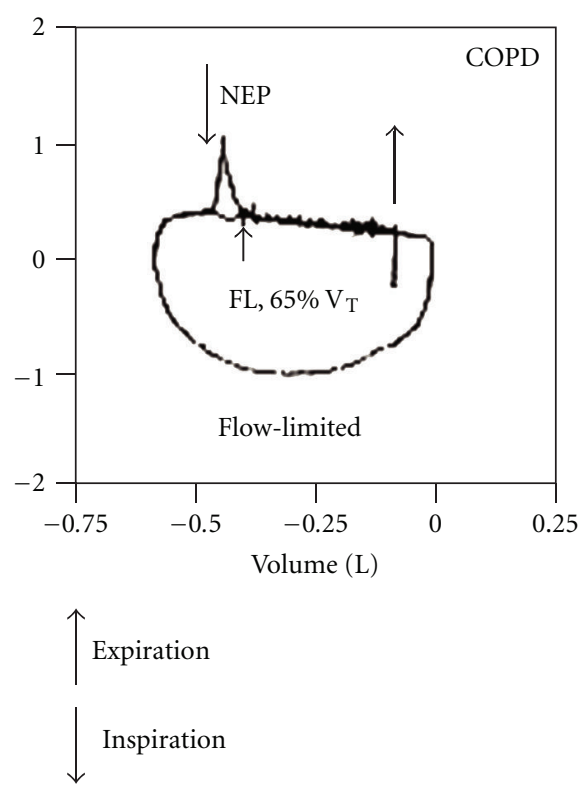

(c)

FIGURE 2: Flow-volume loops of test breaths and preceding control breaths of three representative COPD patients with different degrees of flow-limitation: not flow-limited (NFL) (a), flow-limited (EFL) over less than $50 \% \mathrm{~V}_{\mathrm{T}}$ (b), and flow-limited from peak expiratory flow (EFL) (c). Arrows indicate points at which NEP was applied and removed (modified from [10]).

flow limitation when lung volume changed, a finding which requires confirmation. The method is appealingly simple, not influenced by the upper airway compliance, and like the NEP method, it avoids problems with the preceding volume history of the test breath. Despite initial concerns about the possibility that gas compression in the alveoli would produce false positive results, this does not seem to be a practical problem. However, unlike the NEP method, it is virtually impossible to squeeze at the precise of expiration. Thus far this technique has not been widely applied despite its relative simplicity.

\section{Forced Oscillation Technique (FOT)}

Another approach for detecting $\mathrm{EFL}_{\mathrm{T}}$ has been the forced oscillation technique (FOT) previously applied to look at the frequency dependence of resistance in a range of lung diseases and now available commercially in a modified form using impulse oscillometry $[48,49]$. The principle here is that flow limitation will only be present in patients with obstructive pulmonary disease during expiration. Normally oscillatory pressures generated by a loud-speaker system at the mouth are transmitted throughout the respiratory system, and by studying the resulting pressures which are in and out of phase with the signal, both the respiratory system resistance and reactance (a measure of the elastic properties of the system) can be computed. When flow limitation occurs, wave speed theory predicts that a choke point will develop within the airway subtended by that "unit" of the lung. In these circumstances, the oscillatory pressure applied at the mouth will no longer reach the alveoli and the reactance will reflect the mechanical properties of the airway 
wall rather than those of the whole respiratory system. As a result, reactance becomes much more negative and there is a clear within breath difference between inspiration and expiration. Dellacá and colleagues [49] used this property to investigate the distribution of changes in intrabreath reactance in normal subjects and COPD patients who were instrumented with balloon catheters. In a recent study Dellacá et al. [50] found a good agreement between NEP and FOT despite the fact that the FOT method may detect regional as well as overall $\mathrm{EFL}_{\mathrm{T}}$. NEP detects the condition in which all possible pathways between airway opening and the alveoli are choked. When this occurs, the total expiratory flow is independent of the expiratory pressure, a condition of "global" expiratory flow limitation. In contrast, FOT assesses the amount of the lung that is choked during expiration only. This measures "regional" flow limitation, and a threshold value may indicate when the regional flow limitation reaches the condition of "global" flow limitation. Therefore, when "global" expiratory flow limitation is reached, the two techniques should produce the same response [50].

It does appear to hold considerable promise, but to date, only a few studies to detect $\mathrm{EFL}_{\mathrm{T}}$ with this method have been reported. On the other hand, FOT is very complex, expensive as it requires the special FOT equipment, and time consuming.

\section{Technegas Method}

Technegas is an aerosol of ${ }^{99 \mathrm{~m}} \mathrm{Tc}$-labeled carbon molecules with small diameter $(<0.01 \mu \mathrm{m})$ [19] capable of depositing even in the most peripheral regions of the lung. Pellegrino et al. [19] used the inhalation of Technegas to reveal sites ("hot spots") of EFL $\mathrm{T}_{\mathrm{T}}$ after induced bronchocontsriction in asthmatic patients. During forced expiration, the flowlimiting segment is known to be located first in the large intrathoracic airways and then to move peripherally. However, the present scintigraphic technique cannot precisely define the anatomical location of the flow-limiting segment during tidal breathing. Therefore, what the "hot spots" represent appears to be uncertain. The authors claim that this technique is useful to detect "regional" $\mathrm{EFL}_{\mathrm{T}}$ well before the NEP and submaximal expiratory manoeuvre techniques.

\section{Breath-by-Breath Method}

The most recent method to detect $\mathrm{EFL}_{\mathrm{T}}$ is the one using breath-by-breath quantification of progressive airflow limitation during exercise applied in stable COPD patients [51]. The authors have noted that during heavy exercise in COPD patients, dynamic airways compression leads to a progressive fall in intrabreath flow. This is manifested by an increasing concavity in the spontaneous expiratory flowvolume (SEFV) curve. The new method consists in quantifying the SEFV curve configuration breath-by-breath during incremental exercise utilizing a computerized analysis. For each breath's SEFV curve, points of highest flow and endexpiration were identified to define a rectangle's diagonal. Fractional area within the rectangle below the SEFV curve was defined as the "rectangular area ratio" (RAR). RAR $<0.5$ signifies concavity of the SEFV curve. However, this method may be useful only during exercise because inspection of SEFV curve during resting breathing is not a reliable means in detecting $\mathrm{EFL}_{\mathrm{T}}$ [41]. Severe COPD patients often exhibit a mechanically active expiration, which is characterized by abdominal activity. This necessarily affects the shape of SEFV curve, making it concave with respect to the volume axis, even in the absence of $\mathrm{EFL}_{\mathrm{T}}$ [52].

\section{Conclusions}

The newer aforementioned techniques represent a substantial advance on traditional approaches which compared tidal and maximal flow-volume loops or even the more robust but time-consuming method of determining partial expiratory flow-volume loops. By freeing both parts, the doctor and the patient, from the limitations of the oesophageal balloon catheters and body plethysmograph, they have opened up a new era in understanding modern physiological principles like the tidal expiratory flow limitation [8, 43, 44]. Among the available physiological techniques to detect $\mathrm{EFL}_{\mathrm{T}}$, the NEP should probably be regarded as the new gold standard. This view is supported by the data obtained from the NEP's application in a wide variety of settings $[8,43,44]$. However, extensive comparisons between these different methods are needed before the best "test" or combination of techniques can be unequivocally recommended to correctly assess EFL $\mathrm{T}_{\mathrm{T}}$.

\section{References}

[1] N. B. Pride, "Tests of forced expiration and inspiration," in Lung Function Tests: Physiological Principles and Clinical Applications, J. M. B. Hughes and N. B. Pride, Eds., pp. 3-25, WB Saunders, London, UK, 1999.

[2] M. Pecchiari, A. Pelucchi, E. D’Angelo, A. Forest, J. MilicEmili, and E. D'Angelo, "Effect of heliox breathing on dynamic hyperinflation in COPD patients," Chest, vol. 125, no. 6, pp. 2075-2082, 2004.

[3] C. Brighenti, P. Barbini, G. Gnudi, G. Cevenini, M. Pecchiari, and E. D'Angelo, "Helium-oxygen ventilation in the presence of expiratory flow-limitation: a model study," Respiratory Physiology and Neurobiology, vol. 157, no. 2-3, pp. 326-334, 2007.

[4] E. D’Angelo, P. Santus, M. F. Civitillo, S. Centanni, and M. Pecchiari, "Expiratory flow-limitation and heliox breathing in resting and exercising COPD patients," Respiratory Physiology and Neurobiology, vol. 169, no. 3, pp. 291-296, 2009.

[5] J. Milic-Emili, "Does mechanical injury of the peripheral airways play a role in the genesis of COPD in smokers?" COPD, vol. 1, no. 1, pp. 85-92, 2004.

[6] J. Milic-Emili, R. Torchio, and E. D’Angelo, "Closing volume: a reappraisal (1967-2007)," European Journal of Applied Physiology, vol. 99, no. 6, pp. 567-583, 2007.

[7] E. D’Angelo, N. G. Koulouris, P. Della Valle, G. Gentile, and M. Pecchiari, "The fall in exhaled nitric oxide with ventilation at low lung volumes in rabbits: an index of small airway injury," Respiratory Physiology and Neurobiology, vol. 160, no. 2, pp. 215-223, 2008.

[8] P. M. A. Calverley and N. G. Koulouris, "Flow limitation and dynamic hyperinflation: key concepts in modern respiratory physiology," European Respiratory Journal, vol. 25, no. 1, pp. 186-199, 2005. 
[9] S. A. Gennimata, A. Palamidas, F. Karakontaki et al., "Pathophysiology of evolution of small airways disease to overt COPD," COPD, vol. 7, no. 4, pp. 269-275, 2010.

[10] L. Eltayara, M. R. Becklake, C. A. Volta, and J. Milic-Emili, "Relationship between chronic dyspnea and expiratory flow limitation in patients with chronic obstructive pulmonary disease," American Journal of Respiratory and Critical Care Medicine, vol. 154, no. 6, pp. 1726-1734, 1996.

[11] C. Tantucci, A. Duguet, T. Similowski, M. Zelter, J. P. Derenne, and J. Milic-Emili, "Effect of salbutamol on dynamic hyperinflation in chronic obstructive pulmonary disease patients," European Respiratory Journal, vol. 12, no. 4, pp. 799-804, 1998.

[12] E. Boni, L. Corda, D. Franchini et al., "Volume effect and exertional dyspnoea after bronchodilator in patients with COPD with and without expiratory flow limitation at rest," Thorax, vol. 57, no. 6, pp. 528-532, 2002.

[13] J. Hadcroft and P. M. A. Calverley, "Alternative methods for assessing bronchodilator reversibility in chronic obstructive pulmonary disease," Thorax, vol. 56, no. 9, pp. 713-720, 2001.

[14] O. Díaz, C. Villafranca, H. Ghezzo et al., "Role of inspiratory capacity on exercise tolerance in COPD patients with and without tidal expiratory flow limitation at rest," European Respiratory Journal, vol. 16, no. 2, pp. 269-275, 2000.

[15] O. Díaz, C. Villafranca, H. Ghezzo et al., "Breathing pattern and gas exchange at peak exercise in COPD patients with and without tidal flow limitation at rest," European Respiratory Journal, vol. 17, no. 6, pp. 1120-1127, 2001.

[16] D. E. O'Donnell, S. M. Revill, and K. A. Webb, "Dynamic hyperinflation and exercise intolerance in chronic obstructive pulmonary disease," American Journal of Respiratory and Critical Care Medicine, vol. 164, no. 5, pp. 770-777, 2001.

[17] N. G. Koulouris, I. Dimopoulou, P. Valta, R. Finkelstein, M. G. Cosio, and J. Milic-Emili, "Detection of expiratory flow limitation during exercise in COPD patients," Journal of Applied Physiology, vol. 82, no. 3, pp. 723-731, 1997.

[18] C. Tantucci, M. Ellaffi, A. Duguet et al., "Dynamic hyperinflation and flow limitation during methacholine-induced bronchoconstriction in asthma," European Respiratory Journal, vol. 14, no. 2, pp. 295-301, 1999.

[19] R. Pellegrino, A. Biggi, A. Papaleo, G. Camuzzini, J. R. Rodarte, and V. Brusasco, "Regional expiratory flow limitation studied with technegas in asthma," Journal of Applied Physiology, vol. 91, no. 5, pp. 2190-2198, 2001.

[20] V. Alvisi, A. Romanello, M. Badet, S. Gaillard, F. Philit, and C. Guérin, "Time course of expiratory flow limitation in COPD patients during acute respiratory failure requiring mechanical ventilation," Chest, vol. 123, no. 5, pp. 1625-1632, 2003.

[21] J. F. Murray, "Ventilation," in The Normal Lung: The Basis for Diagnosis and Treatment of Pulmonary Disease, J. F. Murray, Ed., pp. 83-119, WB Saunders, London, UK, 2nd edition, 1986.

[22] D. L. Fry, R. V. Ebert, W. W. Stead, and C. C. Brown, "The mechanics of pulmonary ventilation in normal subjects and in patients with emphysema," American Journal of Medicine, vol. 16, no. 1, pp. 80-97, 1954.

[23] J. Mead and J. L. Whittenberger, "Physical properties of human lungs measured during spontaneous respiration," Journal of Applied Physiology, vol. 5, pp. 779-796, 1953.

[24] R. E. Hyatt, "The interrelationships of pressure, flow, and volume during various respiratory maneuvers in normal and emphysematous subjects," American Review of Respiratory Disease, vol. 83, pp. 676-683, 1961.

[25] D. G. Leaver and N. B. Pride, "Flow-volume curves and expiratory pressures during exercise in patients with chronic airways obstruction," Scandinavian Journal of Respiratory Diseases. Supplementum, vol. 77, pp. 23-27, 1971.

[26] R. H. Ingram and D. P. Schilder, "Effect of gas compression on pulmonary pressure, flow, and volume relationship," Journal of Applied Physiology, vol. 21, no. 6, pp. 1821-1826, 1966.

[27] D. G. Stubbing, L. D. Pengelly, J. L. C. Morse, and N. L. Jones, "Pulmonary mechanics during exercise in subjects with chronic airflow obstruction," Journal of Applied Physiology Respiratory Environmental and Exercise Physiology, vol. 49, no. 3, pp. 511-515, 1980.

[28] M. Younes and G. Kivinen, "Respiratory mechanics and breathing pattern during and following maximal exercise," Journal of Applied Physiology Respiratory Environmental and Exercise Physiology, vol. 57, no. 6, pp. 1773-1782, 1984.

[29] E. D’Angelo, E. Prandi, and J. Milic-Emili, "Dependence of maximal flow-volume curves on time course of preceding inspiration," Journal of Applied Physiology, vol. 75, no. 3, pp. 1155-1159, 1993.

[30] E. D’Angelo, E. Prandi, L. Marazzini, and J. Milic-Emili, "Dependence of maximal flow-volume curves on time course of preceding inspiration in patients with chronic obstruction pulmonary disease," American Journal of Respiratory and Critical Care Medicine, vol. 150, no. 6, pp. 1581-1586, 1994.

[31] N. G. Koulouris, P. Rapakoulias, A. Rassidakis et al., "Dependence of forced vital capacity manoeuvre on time course of preceding inspiration in patients with restrictive lung disease," European Respiratory Journal, vol. 10, no. 10, pp. 2366-2370, 1997.

[32] C. G. Melissinos, P. Webster, Y. K. Tien, and J. Mead, “Time dependence of maximum flow as an index of nonuniform emptying," Journal of Applied Physiology Respiratory Environmental and Exercise Physiology, vol. 47, no. 5, pp. 1043-1050, 1979.

[33] R. D. Fairshter, "Airway hysteresis in normal subjects and individuals with chronic airflow obstruction," Journal of Applied Physiology, vol. 58, no. 5, pp. 1505-1510, 1985.

[34] J. J. Wellman, R. Brown, and R. H. Ingram, "Effect of volume history on successive partial expiratory flow volume maneuvers," Journal of Applied Physiology, vol. 41, no. 2, pp. 153-158, 1976.

[35] K. C. Beck, K. P. Offord, and P. D. Scanlon, "Bronchoconstriction occurring during exercise in asthmatic subjects," American Journal of Respiratory and Critical Care Medicine, vol. 149, no. 2, pp. 352-357, 1994.

[36] N. G. Koulouris, P. Valta, A. Lavoie et al., "A simple method to detect expiratory flow limitation during spontaneous breathing," European Respiratory Journal, vol. 8, no. 2, pp. 306313, 1995.

[37] J. Boczkowski, D. Murciano, M. H. Pichot, A. Ferretti, R. Pariente, and J. Milic-Emili, "Expiratory flow limitation in stable asthmatic patients during resting breathing," American Journal of Respiratory and Critical Care Medicine, vol. 156, no. 3, pp. 752-757, 1997.

[38] M. H. Jones, S. D. Davis, J. A. Kisling, J. M. Howard, R. Castile, and R. S. Tepper, "Flow limitation in infants assessed by negative expiratory pressure," American Journal of Respiratory and Critical Care Medicine, vol. 161, no. 3, pp. 713-717, 2000.

[39] J. Dimitroulis, D. Bisirtzoglou, S. Retsou et al., "Effect of posture on expiratory flow limitation in spontaneously breathing stable COPD patients," American Journal of Respiratory and Critical Care Medicine, vol. 163, no. 5, 2001, Abstract no. A410.

[40] D. Murciano, A. Ferretti, J. Boczkowski, C. Sleiman, M. Fournier, and J. Milic-Emili, "Flow limitation and dynamic hyperinflation during exercise in COPD patients after single 
lung transplantation," Chest, vol. 118, no. 5, pp. 1248-1254, 2000.

[41] A. Baydur and J. Milic-Emili, "Expiratory flow limitation during spontaneous breathing: comparison of patients with restrictive and obstructive respiratory disorders," Chest, vol. 112, no. 4, pp. 1017-1023, 1997.

[42] D. E. O’Donnell, R. Sanii, N. R. Anthonisen, and M. Younes, "Effect of dynamic airway compression on breathing pattern and respiratory sensation in severe chronic obstructive pulmonary disease," American Review of Respiratory Disease, vol. 135, no. 4, pp. 912-918, 1987.

[43] R. Dueck, "Assessment and monitoring of flow limitation and other parameters from flow/volume loops," Journal of Clinical Monitoring and Computing, vol. 16, no. 5-6, pp. 425-432, 2000.

[44] B. D. Johnson, K. C. Beck, R. J. Zeballos, and I. M. Weisman, "Advances in pulmonary laboratory testing," Chest, vol. 116, no. 5, pp. 1377-1387, 1999.

[45] R. Pellegrino and V. Brusasco, "Lung hyperinflation and flow limitation in chronic airway obstruction," European Respiratory Journal, vol. 10, no. 3, pp. 543-549, 1997.

[46] V. Ninane, D. Leduc, S. A. Kafi, M. Nasser, M. Houa, and R. Sergysels, "Detection of expiratory flow limitation by manual compression of the abdominal wall," American Journal of Respiratory and Critical Care Medicine, vol. 163, no. 6, pp. 1326-1330, 2001.

[47] S. Abdel Kafi, T. Sersté, D. Leduc, R. Sergysels, and V. Ninane, "Expiratory flow limitation during exercise in COPD: detection by manual compression of the abdominal wall," European Respiratory Journal, vol. 19, no. 5, pp. 919-927, 2002.

[48] R. L. Dellacà, "Measurement of respiratory system impedances," in Mechanics of Breathing, A. Aliverti, V. Brusasco, P. T. Macklem, and A. Pedotti, Eds., pp. 157-171, Springer, Milan, Italy, 2002.

[49] R. L. Dellacà, P. Santus, A. Aliverti et al., "Detection of expiratory flow limitation in COPD using the forced oscillation technique," European Respiratory Journal, vol. 23, no. 2, pp. 232-240, 2004.

[50] R. L. Dellacà, N. Duffy, P. P. Pompilio et al., "Expiratory flow limitation detected by forced oscillation and negative expiratory pressure," European Respiratory Journal, vol. 29, no. 2, pp. 363-374, 2007.

[51] S. Ma, A. Hecht, J. Varga et al., "Breath-by-breath quantification of progressive airflow limitation during exercise in COPD: a new method," Respiratory Medicine, vol. 104, no. 3, pp. 389396, 2010.

[52] H. M. Thomas, N. G. Koulouris, P. Valta et al., "Expiratory flow limitation during tidal breathing," European Respiratory Journal, vol. 8, no. 9, article 1624, 1995. 


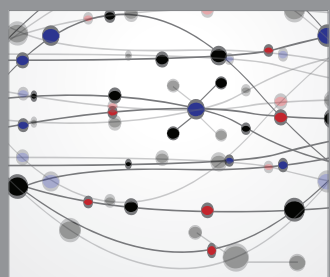

The Scientific World Journal
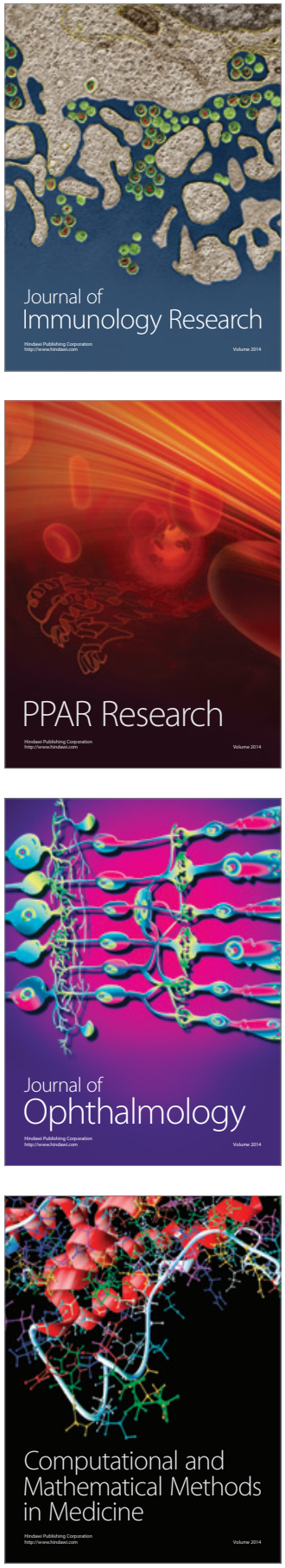

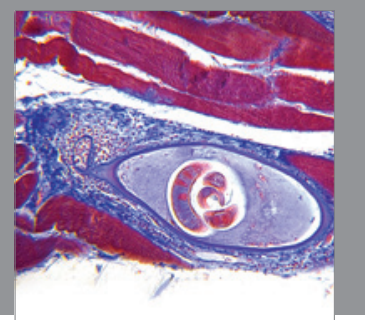

Gastroenterology

Research and Practice
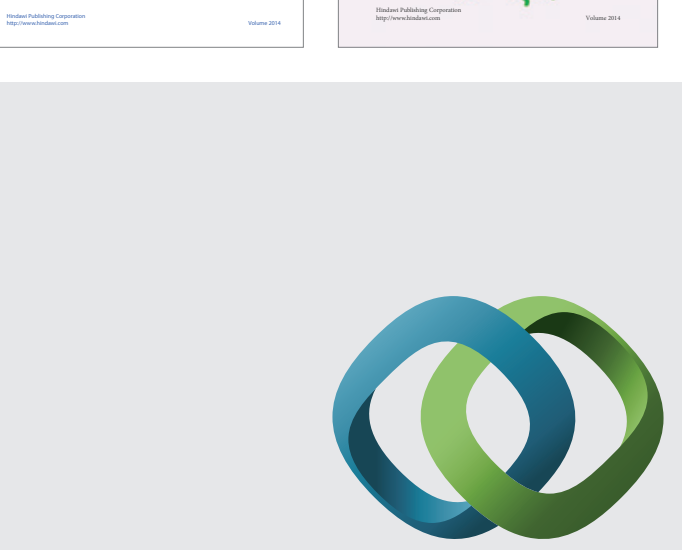

\section{Hindawi}

Submit your manuscripts at

http://www.hindawi.com
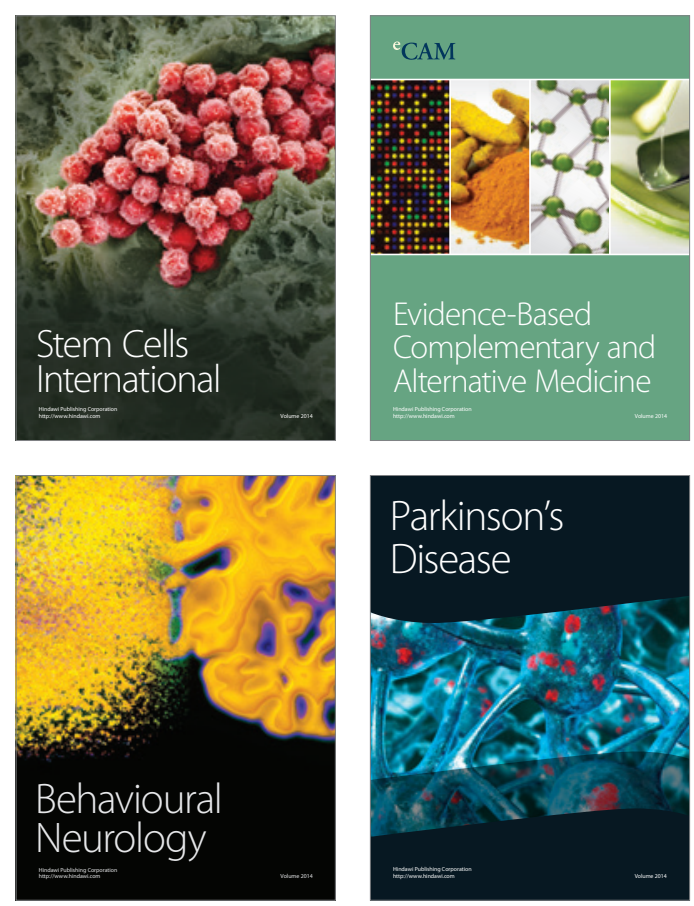

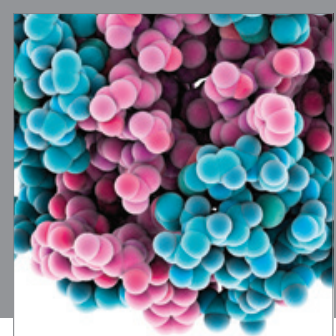

Journal of
Diabetes Research

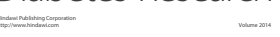

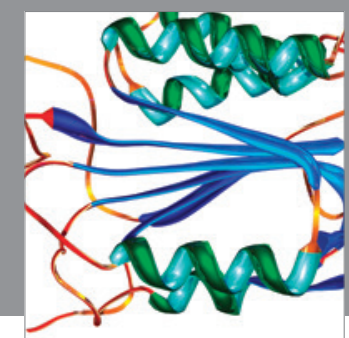

Disease Markers
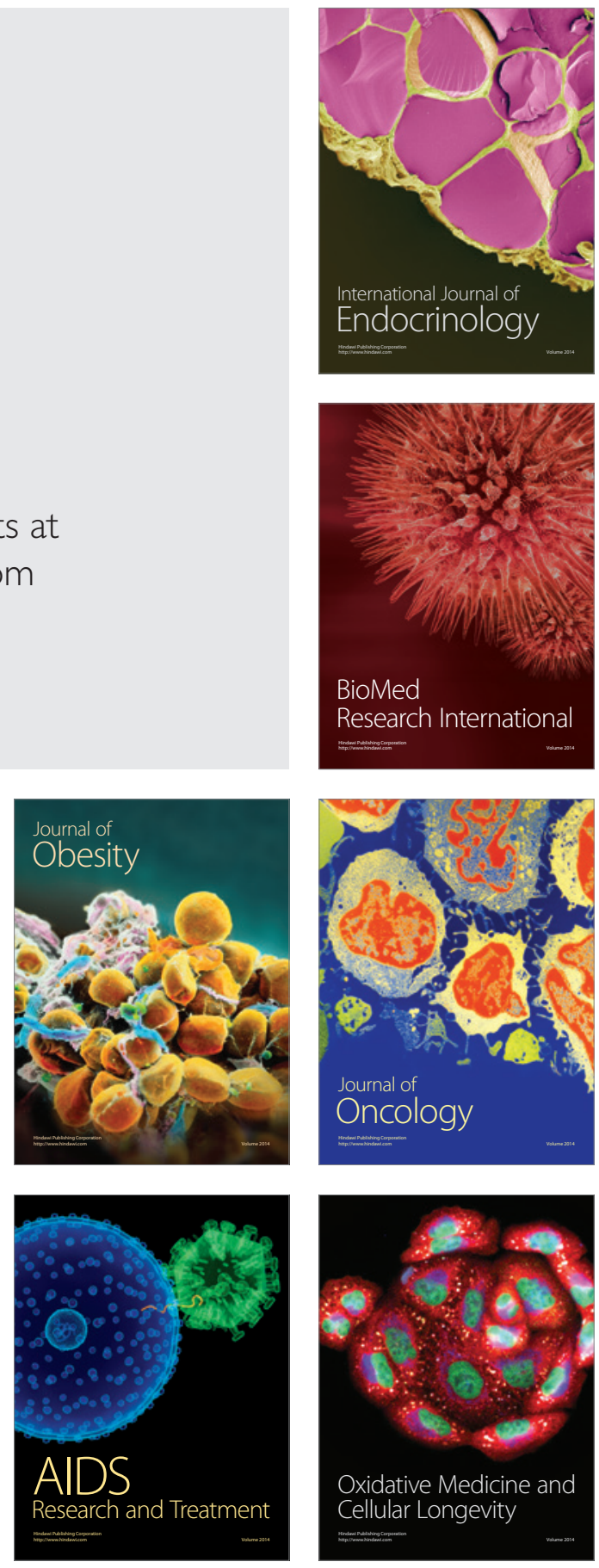